\title{
Students' Perspectives on Undergraduate Research: Obstacles, Experiences, and Tips for a Refined Young Scientist
}

\author{
By Kritleen Bawa, Layan Elfaki and Kevin Tang
}

\section{INTRODUCTION By Kevin Tang}

What is the experience of doing undergraduate research like? What are the common expectations and how do you deal with obstacles that you encounter on the way? What do you get out of it? In this piece, we will discuss the importance of mental health while being a research student, the significance of research experience in an undergraduate career, as well as providing personal experiences to attain optimal performance as an experimenter. In exploring the various aspects of research, we also interviewed an $\mathrm{U}$ of $\mathrm{T}$ PhD Candidate in the department of psychology who worked as a research assistant at Baycrest Hospital for 10 years. Being extensively active in the research community, he had a plethora of research experiences that he loved to share; please find his insight in the " $Q$ and A" after each section.

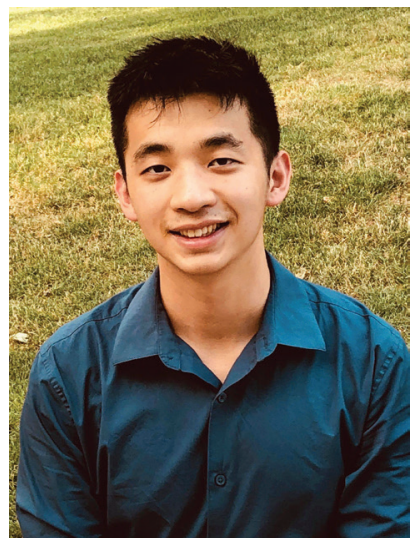

Kevin Tang

\section{MENTAL HEALTH AND RESEARCH \\ By Layan Elfaki}

\section{Setting Expectations}

"Research is not for me". A common phrase I often get when I ask my friends if they're thinking of pursuing graduate school. Though it partially reflects a lack of interest in specific research methodology, it also reflects the mental endurance that the process necessitates. However, there are some aspects of the research process that can be considered beforehand to mitigate the stress and enhance the research experience overall. For instance, before commencing your research project, it's important to have a meeting with your supervisor to set standards and discuss expectations. Through such a meeting, you can set the expectations for work hours, project timeline as well as attendance at lab meetings. Articulating expectations is critical because it enables you to avoid any misunderstandings or conflict that may arise with your supervisor as a result of miscommunication. Discussing these expectations before starting a research project will ultimately aid smooth progression of the project, while fostering positive relationships with your supervisor.

Q: What was the biggest obstacle(s) you encountered in research and how were you able to overcome it?

A: The first obstacle is familiarizing yourself with the workflow, logistic, dynamics of the people. The second obstacle is once you collect data, you have to analyze the data. Don't feel intimidated; this is a part of the learning process, and it is helpful for your CV for the future if you know how to analyze data. In case labs don't offer this opportunity, then you should challenge yourself to ask supervisors to make sense of the analysis. Lastly, the third obstacle is writing it up! Again, challenge yourself by asking your supervisor or grad student. Making a poster is a great idea because you can travel, learn to be succinct, and communicate clearly.

\section{Professional Relationships}

Professional relationships with supervisors and co-workers can be daunting to navigate at first. This can apply whether you're an introvert and aren't comfortable opening up quickly or if you're an extrovert and tend to overshare. However, if you're unsure of where to draw the professional boundary line, it's always safe to initially interact with lab members in a professional manner. Then, depending on how the lab dynamics are, you can adjust your interactions accordingly. In lab environments, your interactions with others become representative of your character which your supervisor witnesses. Based on that as well as your work ethic, they may choose to recommend you to other Pls for graduate school etc. Moreover, the boundary line can also be unclear when handling participant recruitment. In such cases, I've realized that it's best to gauge the participant's interest in engaging in a conversation. This can help you avoid any awkward situations where the participant gets irritated because you're being overly talkative. Be kind, professional and explain instructions clearly, but don't overstep the professional line unless 
the situation calls for it.

Q: How do you maintain professional boundaries with lab supervisor/mates?

A: First, when writing emails, be polite and clear. Try not to sound so obscene or too informal. To establish professional boundaries, set a time if you do want to hang out to build a keen environment. Second, when you go to a hospital or professional setting, you need to be aware of what you are wearing. It doesn't mean you have to wear a suit, but just wear something that is business casual. Third, I recommend making a working account on linkedin, and creating a separation between personal/private and professional profile online. In the future, you can add your coworkers, peers, work friends, just to protect yourself.

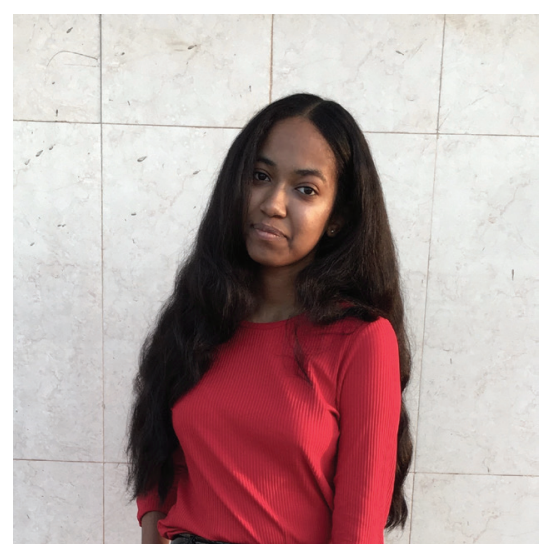

Layan Elfaki

\section{Personal Qualities}

Apart from the technical skills gained through investigating a novel research question, the research process itself facilitates the development of critical personality traits and interpersonal skills. When first starting a research project, having enthusiasm and intending to try your best to execute a task alone can take you far. However, this often comes from being passionate about the type of research you chose to pursue and so, lack of passion can easily lead to disappointing results. To avoid such an outcome, it's critical to begin the search for a research lab at your earliest convenience. Not only does this provide you with the opportunity to explore various options, but it also helps reduce the stress of having to secure a supervisor lastminute. On the other hand, being an experimenter enables development of dependability, time management and scientific communication skills. Presenting your research is one of the most rewarding aspects of the process because not only does it enable you to share your findings with the scientific community, but it also allows you to be comfortable with handling criticism.

Q: What are the most important personal qualities you realized you needed to cultivate to pursue research? A: Patience! You need to have patience because the data may not align with your hypothesis, and you may need to change your tests. Second, be inquisitive, which means being curious of the type of questions you can ask, such as questioning the original goal of the project or taking what is available and analyzing it from a different perspective. Having a curious mind is just as important as being patient. Third, be motivated, as this works not just in research, but also in sports, academia, and life. If you're motivated, it drives you to do things that you're not comfortable with; this includes reaching out to supervisors, making posters, analyzing data, and writing reports.

\section{Obstacles in Research}

When first joining a lab, there's often an initial shock or fear factor due to the novel environment that you must acclimate to. One strategy that l've learned to overcome that initial fear is to see the opportunity as a valuable experience for growth and learning. This change in mindset can help you conquer any challenging academic situation. Similarly, through my own experiences with failing at tasks relating to my research project, I've realized that the most valuable tool is learning to separate my ego from my failures. This includes accepting the fact that one's failures don't necessarily reflect their qualities as an experimenter but rather their lack of knowledge in that specific research topic/methodology. Thus, it becomes imperative to ask for feedback with regards to your performance and implement it to better execute your role as a student researcher.
More importantly, the progress of a research project often depends on having resilience and perseverance in the face of obstacles. It's no secret that the research experience can be cumbersome at times; failing western blots, errors running the Matlab code script, difficulty extracting the eye-tracking data and the list goes on. Because researchers are often exploring novel research topics or methodology outside their expertise, it's almost a given that failure will be encountered at some point in the process. Research also carries a lot of uncertainty and depending on where data analysis leads you, the initial research question may necessitate alteration. In this case, being openminded can provide clarity into ulterior unforseen explanations in addition to the course of action. Once more, perspective becomes important here, and the act of simply changing your mindset to "I can conquer anything if I try hard enough" can lead to achieving one's goals while facilitating personal growth - given that the outcome is within reach, of course.

Q: What are a few lessons you've learned from your experience with research?

A: I learned that things will fall into place if you plan ahead. Planning ahead means you have to have a goal, whether it's short term or long term, so one goal gets you another goal. Doing this by yourself is one thing, but being surrounded by motivated people is another. So reach out to people who can provide feedback on your project. Sometimes, you might end up collaborating with someone. In summary, have short term goals, have long term goals, and be surrounded by motivated people to collaborate with and don't be shy to reach out to your supervisors.

\section{RESEARCH AS A TOOL TO FIND WHAT YOU LIKE (OR DON'T LIKE) By Kritleen Bawa}

Research is thought to be an essential part of one's life science undergraduate 
career. Although it takes a lot of mental and physical energy to pursue research in combination with undergraduate classes and extracurriculars, research experience can be an effective tool to not only understand the science outside of the classroom but also yourself. Research experiences can differ in many ways, and having first hand experience can allow you to determine the kind of research that you want to pursue. In addition, all these different experiences, positive or not so positive, ultimately shape you into the person and young scientist that you become.

Some of the different variables that can affect your research experience are described below. These include the kind of research methodology (wet vs dry labs), lab size (big vs small lab), style of supervision (micro vs macro managing $\mathrm{PI}$ ), topic of the research, and whether research is something you want to continue with (grad school or career). Having an understanding of these different variables can help you choose an experience that you think might be the best for you, but only several first hand experiences can clear all your doubts regarding research in a lab.

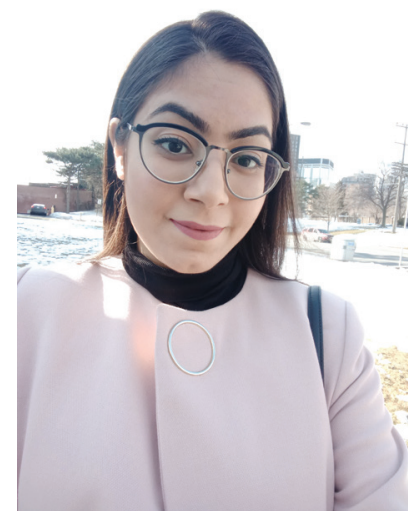

Kritleen Bawa

Q: What kind of experiences helped you decide that research was an ideal career for you?

A: Those experiences included being involved in different projects, conducting research, recruiting participants, analyzing data, writing it, presenting it at institutional rounds, and doing posters. All these help motivate you since you're surrounded by research opportunities. As well, you should be willing to accept failure--your data may not be what you want, and it can take longer. These types of experiences give you an outlook. If you get to formally present your data, that's one of the best things to commit you to a long term relationship with research. This is because you have more questions, not only do questions appear in readings but also in the people you meet. The bottom line is deliver your data: if you can deliver your data, you would be interested in research.

\section{"You are your own supervisor, so you have to manage your own workload."}

a) Research methodology: Starting in first year, laboratory courses in life science such as biology, chemistry, and physics provide students with a taste of what it is like to work in a research lab. Chemistry labs usually use wet lab methodology, biology labs can be a combination of both wet (cell cultures, microscopy) and dry (EEG, action potentials), and physics labs are usually dry labs (electric cells, elasticity, flight). These experiences can be used to determine whether you will enjoy working in a wet lab or a dry lab setting.

b) Lab size: Lab work is usually done in groups and different labs collaborate with each other as well. Labs can be small ranging from a few students, or a student and a research assistant/ health practitioner, to a large lab consisting of 10-20 people, half students and half research assistants or mostly research assistants and only a couple of students. In small labs, one can usually get more one on one time with the supervisor but does not have a huge support group besides the supervisor and at times when you have a minor query, you might not think it is important to ask your supervisor and have to find the answer yourself. In a large lab, although you have people to answer your minor questions and train you more thoroughly, you will likely not be able to form a very close relationship with your supervisor. Obviously there are exceptions, some supervisors can have a big lab and still give you enough one on one time, and supervisors with small labs may still have collaborators who could teach you and answer your day to day questions. But whatever the size may be, teamwork and collaboration is essential for good research. And so being a good team player, networking at events, and asking questions helps you become a better scientist.

c) Supervision style: Some students prefer a supervisor who is available to meet with them and has an open-door style of teaching, a supervisor who is hands off but available when you need them. But some might work best with a supervisor who gives them direct tasks and meets with them regularly to discuss the progress on those tasks. People thrive under different styles of supervision: micro or macro management. Experiencing these two styles first hand can help you decide which one is your preferred style of learning. Many graduate students agree that a good supervisor who is supportive of their students and aids in their students' growth may be more important than the topic of the research project itself when choosing a lab for graduate studies.

Q: What kind of lab environment and supervision do you thrive in?

A: I've experienced both sides. If you have nothing on your plate, and you have a supervisor that micromanages you, that should push you to recruit as many people, so that's a good thing. If you have a lot on your plate, then another supervisor style is to let you be on your own because they know you can do it. Because if you have lots on your agenda, then it's hard to get something done on the next day, but if they let you be independant, then that works for you. You are your own supervisor, you need to know when to push yourself, and when to maximize your efficiency, and you don't wait around for someone to yell at you, that's up to you depending on your plate. You need to communicate with your supervisor ahead of time that these are your deadlines, and work 
hard to get it done. Don't shy away from voicing your workload. Bottom line: you are your own supervisor, so you have to manage your own workload.

d) Topics you are passionate about: It can be really hard to know the topics that you are passionate about in first year, and even if you do know, you might not be experienced enough to get a position in a lab that works on a topic of your choice. What most undergrads end up doing is keeping their options open. It is better not to be too picky when applying for research experiences in first or second year. The whole point of doing research during undergraduate is to expose yourself to different things and then decide what it is that you like the most. Apply to labs that you think you may find interesting and take up the opportunities that come your way. You must gain experience to learn what you like. Once you are in third year, you will have a better understanding of the topics and the supervisors that you would like to work with. At this point, write an email to these supervisors and tell them why you would like to work with them. Emails need to be short but must convey your message effectively.

Q: How did you discover the topics that you were passionate about and how did you approach professors working in that field?

A: In your second year, if you take an intro course, you can discover topics that are interesting. And when you go to seminar courses, then you can find professors who are interested in that topic. So you can learn from courses that professors teach. You can learn from TA's that give guest lectures. Those experiences can mold you to the type of research you can do. If you are an $R A$, you can learn about topics in your project. l'd recommend against taking a gap year. If you are ever doubtful of going to grad school because you don't know what you're doing, it helps you to put yourself in an environment where they are extremely motivated, learn new skills, and get a Master's degree, and get more qualified!

e) Grad school or career: If you realize that research may be something that you like, you might consider graduate school, or if you would like to gain more experience, you might want to work as a research assistant after finishing your undergraduate degree. Once in graduate school, you should ask yourself whether you would continue down the road of academia (would you like doing your supervisor's job?) or would you like to work in the industry (go to seminars hosted by several different departments, look online for jobs with your degree, talk to previous graduate students).

Q: What is the difference between working as an RA and a graduate student in a lab?

A: Being a grad student, you can't afford to have a lazy mindset, as an RA you can afford to be lazy because you have a job, you are paid to do something, your supervisor always has something for you to do. Every day as an RA, you can relax after work. As a grad student, that degree of freedom is not as free because you still need to work, mark papers, read them, prepare for lab meetings, apply for scholarships--there's always something for you to do. So you are your own supervisor as a grad student-you have your own expectations. But as an RA, you are defined by the task you are given by your supervisor. You have more flexibility to do things that you want, you make more money. As a grad student, you constantly have deadlines. The good thing being a grad student, you are in a position to learn new things--you are surrounded by your peers, you can work on a project, learn new skills to help your research, from programming, coding, and learning new statistical methods. The bottom line is that you need experience to decide what you like and what your preferences are. Dr. Taverna, a neuroscience professor of the Human Biology Department at the University of Toronto once told me that, "every experience teaches you something, and experiences are never a waste. If you did not like something, at least now you know it's not for you." I have lived by this advice throughout my undergraduate and graduate career. Objective knowledge only comes from experience, so never think that an experience is a waste of your time. Experience is the best kind of teacher. It helps you understand yourself better and you come out of it as a better version of yourself.

\section{EMAIL WRITING TIPS}

- Keep it short and sweet; no more than two paragraphs

- It must be addressed to the professor you are interested in working with, and must talk about one of their research articles that you found interesting

- First paragraph: Tell them your name and why you are emailing them right away. Tell them what year you are in and your major. Also mention a research course or award that you are planning on applying for.

- Second paragraph: Pick an article that they wrote that you found interesting, comment on a result that fascinated you or that you would like to learn more about. Also mention why you are interested in this particular topic or article. This paragraph should not be longer than 6-7 sentences.

- Follow up with them after a week if you get no response.

- And repeat!

Received: April 12, 2020

Accepted: September 22, 2020

Published online: December 30, 2020 